\title{
Uji Lapang Mesin Pemarut Sagu Tipe Silinder Bertenaga Motor Bakar Bensin
}

\section{Field Test of Cylinder Type Sago Rasping Machine Powered by Gasoline Engine}

\author{
Darma $^{1 *}$, Arif Faisol ${ }^{2}$, Mario M. Selano ${ }^{3}$ \\ 1,2 Jurusan Teknik Pertanian dan Biosistem, Fakultas Teknologi Pertanian Unipa \\ J1. Gunung Salju amban, Manokwari 98314. \\ ${ }^{3}$ Jurusan Teknologi Hasil Pertanian, Fakultas Teknologi Pertanian Unipa \\ Jl. Gunung Salju amban, Manokwari 98314. \\ *Email: darmabond@gmail.com
}

\begin{abstract}
The agroindustry machinery workshop of Fateta Unipa has produced various prototypes of sago rasping machine, one of which is a cylindrical type using a rasping system with debarking sago trunk. A prototype of the machine must have field test in order to know its performance in real conditions. The purpose of this study was to conduct field testing of a cylinder type sago rasping machine powered by gasoline engine. The field test was carried out in Masni District, Manokwari Regency involving 2 families of sago farmer. The machine's performance under field condition was evaluated by measuring parameters (a) rasping capacity, (b) starch percentage, (c) starch yield, (d) starch loss in waste and (e) fuel consumption. The results show that all parts of the machine are functioning properly and farmers can easily operate the machine. During the test there were no technical constraints. The performance of the machine under field condition are (a) rasping capacity 620 $\mathrm{kg} / \mathrm{hour}$, (b) starch percentage 41.5\%, (c) starch yield $479 \mathrm{~kg} /$ trunk, (d) starch loss in waste 6.79\% and $8 \%$, (e) fuel consumption 1.05 litre/hour.
\end{abstract}

Keywords:Sago rasping machine, cylinder type, field test, starch percentage, rasping capacity

\begin{abstract}
Abstrak
Bengkel permesinan agroindustri Fateta Unipa telah menghasilkan berbagai prototype mesin pemarut sagu, salah satu diantaranya yaitu tipe silinder menggunakan sistem pemarutan dengan pengupasan kulit batang. Suatu prototype mesin wajib dilakukan uji lapang agar diketahui kinerja mesin pada kondisi yang sesungguhnya (real condition). Tujuan penelitian ini adalah pengujian lapangan mesin pemarut sagu tipe silinder bertenaga motor bakar bensin. Uji lapang dilakukan di Distrik Masni, Kabupaten Manokwari dengan melibatkan 2 keluarga pemilik dusun sagu. Evaluasi kinerja mesin pada kondisi lapang dilakukan dengan mengukur parameter (a) kapasitas pemarutan, (b) rendemen pati, (c) hasil pati, (d) kehilangan pati pada ampas dan (e) konsumsi bahan bakar bensin. Dari hasil uji lapang menunjukkan bahwa semua bagian mesin berfungsi dengan baik dan petani dengan mudah dapat mengoperasikan mesin tersebut. Selama pengujian tidak ditemui adanya kendala teknis. Performansi mesin pada kondisi lapang yaitu: (a) kapasitas pemarutan $621 \mathrm{~kg} / \mathrm{jam}$, (b) rendemen pati 41,5\%, (c) hasil pati $479 \mathrm{~kg} /$ pohon, (d) kehilangan pati pati pada ampas 6,79\% dan (e) konsumsi bahan bakar 1,05 liter/jam.
\end{abstract}

Kata kunci: Mesin pemarut sagu, tipe silinder, uji lapang, rendemen pati, kapasitas pemarutan 


\section{PENDAHULUAN}

Pengembangan agroindustri pengolahan sagu di Papua dan Papua Barat mempunyai prospek yang cerah karena memiliki bahan baku yang melimpah. Hal ini didukung dan sejalan dengan kebijakan pemerintah daerah yang telah menobatkan sagu sebagai komoditas unggulan lokal dalam upaya mendukung ketahanan pangan (food security) dan kedaulatan pangan (food sovereignty). Berkembangnya agroindustri sagu akan memberikan dampak: (a) meningkatkan nilai tambah hasil panen sagu, baik untuk konsumsi langsung maupun untuk bahan baku agroindustri lanjutan, (b) meningkatkatkan jaminan mutu dan harga sehingga tercapai efisiensi kegiatan agribisnis, (c) mengembangkan diversifikasi produk sebagai upaya penanggulangan kelebihan produksi atau kelangkaan permintaan pada periode tertentu, (d) sebagai wahana pengenalan, penguasaan dan pemanfaatan teknologi sekaligus sebagai wahana peran serta masyarakat dalam menerapkan budaya industri melalui penciptaan wirausaha baru dan swadaya petani.

Provinsi Papua dan Papua Barat memiliki potensi sagu yang sangat besar. Sekitar 50\% dari potensi sagu dunia terdapat di Indonesia, dan sekitar $90 \%$ dari potensi sagu indonesia berada di kedua provinsi ini (Jong dan Widjono, 2007). Menurut Bintoro (2011), lebih dari $50 \%$ potensi sagu dunia berada di Indonesia dan lebih dari $95 \%$ sagu indonesia tersebut tumbuh di kawasan bagian timur terutama Papua. Flach (1997) memperkirakan luas areal sagu (Metroxylon sagu) di Papua dan Papua Barat sekitar 1.214.000 ha yang sebagian besar (99\%) berupa hutan sagu alam (natural sago forest). Bahkan menurut Djoefrie dkk. (2014) luas area sagu di papua 4.700.000 ha dan 510.000 ha terdapat di Papua Barat. Matanubun dan Maturbongs (2006), memperkirakan luas areal sagu di Papua dan Papua Barat sekitar 1.471.232 ha dengan potensi produksi pati kering sekitar 12.035.000 ton/tahun.

Walaupun potensi sagu di kedua provinsi ini sangat besar, namun sampai saat ini pemanfaatannya masih sangat rendah dibandingkan dengan potensi yang ada. Sebagian besar pohon sagu siap panen dibiarkan mati di tempat tumbuhnya karena tidak diolah oleh pemiliknya. Berbeda dengan tanaman tahunan lainnya yang akan tumbuh secara terus menerus, sagu akan mati secara perlahan setelah fase reproduksi dan pati yang terkandung dalam batang akan hilang percuma. Hal ini berarti jutaan ton pati yang terkandung dalam batang sagu tidak dimanfaatkan dan hilang sia-sia setiap tahunnya. Matanubun dan Maturbongs (2006) memperkirakan bahwa pemanfaatan sumberdaya sagu di Papua kurang dari $5 \%$ dari potensi yang ada meskipun kebutuhan akan pati sagu terus meningkat dari tahun ke tahun baik untuk kebutuhan dalam negeri maupun permintaan dari luar negeri. Rendahnya pemanfaatan sagu ini terutama disebabkan karena sebagian besar pengolahan sagu dilakukan oleh masyarakat secara tradisional, dan juga karena lokasi areal sagu umumnya terletak di daerah marginal dengan kondisi geografi dan demografi yang tidak menunjang serta sarana produksi yang sangat terbatas. Untuk menanggulangi kendala ini, perlu dikembangkan untuk kemudian diintroduksi ke masyarakat mesin pengolahan sagu yang harganya terjangkau di tingkat petani, menggunakan teknologi yang mudah diadopsi oleh masyarakat namun efisien dalam penggunaannya.

Tahapan yang membutuhkan curahan waktu dan tenaga paling besar dalam pengolahan sagu secara tradisional yaitu penghancuran empulur batang (pith), yang oleh masyarakat Papua dan Papua Barat dikenal dengan istilah tokok sagu. Proses tokok sagu dilakukan dengan menggunakan tokok (adze) suatu alat sejenis palu yang prinsip kerjanya mengkombinasikan gerakan menumbuk (pounding), memotong (cutting) dan menggaru (scrapping) yang mengakibatkan jaringan empulur terpotongpotong menjadi ukuran kecil sehingga partikel pati terbebas dan dapat dipisahkan pada saat proses ekstraaksi. Rata-rata waktu yang diperlukan untuk penokokan adalah 53,22\% dari total waktu yang diperlukan untuk pengolahan, dan 38,92 \% untuk peremasan (Darma, 2011). Penggunaan mesin pemarut sagu untuk menggantikan alat tokok dapat meningkatkan kapasitas penghancuran empulur batang sampai 50 kali lipat, tergantung tipe mesin pemarut. Pada penelitian-penelitian terdahulu (Darma dkk, 2014; 2015; 2017; 2019) telah menghasilkan prototype mesin pemarut sagu tipe silinder bertenaga motor bakar bensin. Mesin-mesin tersebut telah diuji kinerjanya dan bahkan telah 
digunakan di beberapa daerah yang pengadaannya baik secara swadaya maupun difasilitasi oleh pemda setempat, namun belum dilakukan uji lapang (field test). Tujuan penelitian ini yaitu uji lapang mesin pemarut sagu tipe silinder bertenaga motor bakar bensin. Dari hasil penelitian ini akan diketahui performa mesin pada kondisi lapang atau kondisi yang operasional (real condition) sehingga dapat dijadikan dasar dalam penerapannya di suatu lokasi.

\section{METODOLOGI}

\section{Waktu dan tempat}

Penelitian ini terdiri dari 2 tahap yaitu (1) pembuatan konstruksi mesin pemarut sagu tipe silinder bertenaga motor bakar dan (2) uji lapang. Pembuatan konstruksi mesin pemarut sagu dilaksanakan di bengkel Permesinan Agroindustri, Jurusan Teknologi Pertanian, Fateta Unipa. Beberapa bagian alat dibuat di bengkel Arema Manokwari yang memiliki fasilitas peralatan memadai. Uji lapang dilakukan di Kampung Masni, Distrik Masni, Kabupaten Manokwari.

\section{Bahan dan alat}

Peralatan yang digunakan terdiri dari (1) peralatan untuk pembuatan konstruksi mesin pemarut berupa peralatan perbengkelan standard yaitu mesin bubut, mesin las listrik, gurinda, saw mill, bor listrik, ragum, meteran, tang, dan berbagai ukuran kunci pas/ring serta obeng. (2) peralatan untuk uji lapang mesin yaitu timbangan duduk, stop watch, saringan pati manual 100 mesh, alat ekstraksi pati tradisional, blender, cahain saw, kampak, pisau dapur, parang, wadah penampung hasil parutan dan pati, karung plastik dan terpal.

Bahan yang digunakan untuk pembuatan konstruksi mesin parut sagu adalah besi siku 5 $\mathrm{cm} \times 5 \mathrm{~cm} \times 0,5 \mathrm{~cm}$, pelat stainless steel SS 304 tebal $2 \mathrm{~mm}$, pelat stainless steel SS 304 tebal $1 \mathrm{~mm}$, poros as SS $201 \varnothing 25,5 \mathrm{~mm}$, elektroda las listrik RB 2,6 dan NSN 308, as
SS 201 Ø $4 \mathrm{~mm}$, bearing unit UCP 205, motor bakar bensin (engine) Honda GX 160, 5,5 hp,

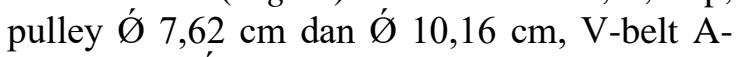
49 , silinder $\varnothing 15 \mathrm{~cm}$ panjang $22 \mathrm{~cm}$ dari kayu akasia, dan engsel bubut $\varnothing 12 \mathrm{~mm}$. Bahan untuk uji lapang berupa empulur batang sagu dan air bersih untuk ekstraksi pati.

\section{Pembuatan mesin pemarut sagu tipe silinder bertenaga motor bakar bensin}

Pada penelitian ini dibuat 2 unit mesin pemarut sagu dengan spesifikasi yang sama untuk kemudian dilakukan pengujian lapang secara simultan. Secara keseluruhan, mesin ini dari 7 komponen utama yaitu: (1) Rangka utama (frame), (2) Motor penggerak, berupa motor bakar bensin 4 tak, 6.5 HP (honda GX 160T), (3) Hopper berfungsi untuk mengarahkan bahan berupa empulur sagu ke komponen silinder penghancur, (4) Silinder penghancur, terbuat dari kayu mahoni yang dipasangi gigi-gerigi (5) Komponen transmisi daya, menggunakan pulley dan V-belt, (6) Saluran pengeluaran hasil parutan (unloader), (7) penutup silinder.

Komponen fungsional dari mesin parut sagu ini berupa silinder penghancur yang berfungsi untuk menghancurkan empulur batang sagu menjadi partikel-partikel yang berukuran kecil (fine) sehingga pati yang terdapat dalam sel dapat dipisahkan pada proses ekstraksi. Silinder penghancur terbuat dari kayu akasia, ukuran panjang $20 \mathrm{~cm}$ dan diameter $15 \mathrm{~cm}$. Gigi parut berupa as stainlesssteel SS 201 berdiameter $0,4 \mathrm{~cm}$, dipasang pada permukaan keliling silinder dengan jarak antar gigi $2,5 \mathrm{~cm} \times 2,5 \mathrm{~cm}$ dan tinggi $2 \mathrm{~cm}$ dari permukaan silinder. Pengaturan gigi parut dibuat sedemikian rupa sehingga pada waktu proses pemarutan berlangsung, semua gigi berfungsi efektif dan tidak ada bagian empulur yang tidak terparut (Darma dkk., 2014; 2017). Pada Gambar 1. ditampilkan mesin pemarut sagu yang telah selesai dibuat dan siap dibawa ke lapang untuk pengujian. 

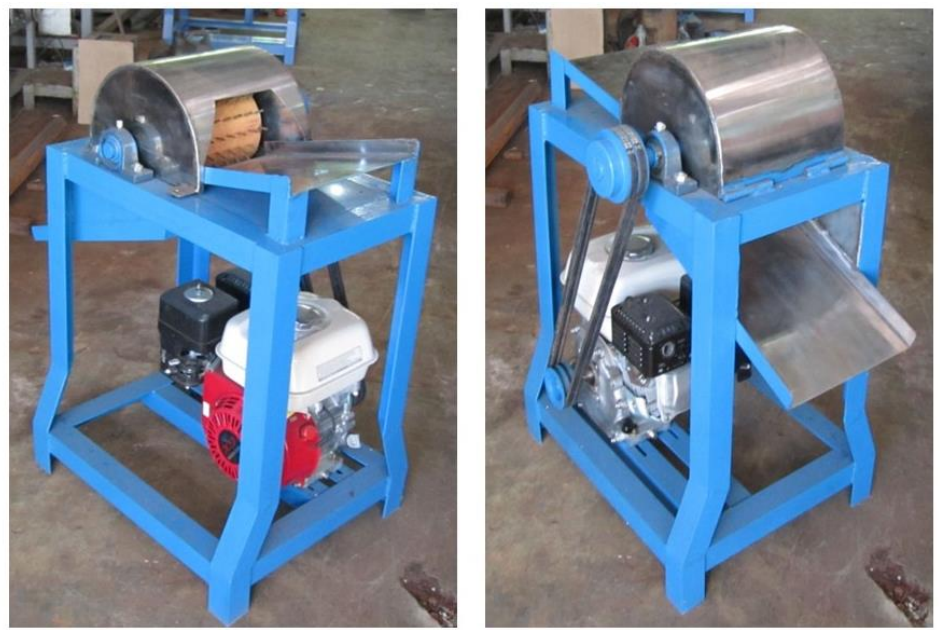

Gambar 1. Mesin pemarut sagu tipe silinder siap untuk pengujian lapang

\section{Pengujian lapang dan analisis data}

Pengoperasian mesin dilakukan oleh masyarakat setempat (pemilik dusun sagu terpilih) dengan terlebih dahulu dilatih oleh tim peneliti. Bagan alir prosedur pengujian lapang ditampilkan pada Gambar 2. Pada penelitian ini melibatkan 2 petani yang berbeda, masing-masing menggunakan 1 unit mesin dengan spesifikasi yang sama. Evaluasi kinerja mesin pada kondisi lapang dilakukan dengan mengukur variabel (1) kapasitas pemarutan, (2) rendemen pati, (3) hasil pati, (4) kehilangan pati pada ampas (starch losses) dan (5) konsumsi bahan bakar.Data hasil pengukuran untuk semua variable pengamatan dianalisis secara tabulasi.

Prosedur pengukuran untuk masingmasing variabel pengamatan yaitu sebagai berikut:

\section{Kapasitas pemarutan}

Sebelum proses pemarutan, terlebih dahulu log-log batang sagu dikupas kulitnya (debarking) kemudian log dibelah-belah agar sesuai untuk proses pemarutan. Proses pemarutan dilakukan dengan menempelkan dan mendorong potongan-potongon empulur batang ke permukaan silinder penghancur. Hancuran empulur hasil parutan (rasped pith/repos) (Cecil, 1992; Manan dkk., 2011) yang oleh masyarakat setempat disebut ela, selanjutnya dikumpulkan dan ditimbang. Kapasitas pemarutan dihitung menggunakan persamaan (1):

$$
R C=\frac{m_{R}}{t}
$$

$R_{C}:$ kapasitas pemarutan $(\mathrm{kg} / \mathrm{jam})$

$m_{R}$ : massa empulur hasil parutan/repos $(\mathrm{kg})$

$t$ : waktu pemarutan (jam).

\section{Rendemen pati (starch percentage)}

Empulur batang sagu hasil parutan/ela (repos) selanjutnya diproses lebih lanjut menggunakan alat ekstraksi pati manual menggunakan saringan dari kain safir (lubang sekitar 200 micron) untuk mengekstrak pati yang terkandung pada empulur. Proses ekstraksi diawali dengan memasukkan repos ke dalam alat penyaring berbentuk kotak dan ditambahkan air secara terus menerus sambil dilakukan pengadukan dan peremasan secara manual. Selama proses ekstarksi berlansung, butiran pati terpisah dari ampas lalu kemudian mengalir ke wadah pengendapan pati. Proses ini dihentikan saat aliran suspensi dari saringan telah jernih. Hasil suspensi pati dalam wadah pengendapan dibiarkan 5 jam untuk pengendapan pati. Rendemen pati dihitung dengan menggunakan persamaan (2):

$$
S P=\frac{m_{S}}{m_{R}} \times 100 \%
$$

$S P$ : rendemen pati (\%)

$m_{S}:$ massa pati basah $(\mathrm{kg})$

$m_{R}$ : masa repos $(\mathrm{kg})$

\section{Hasil/produksi pati (starch yield)}

Hasil pati basah adalah massa total pati yang diperoleh dari proses pengolahan per 
pohon, ditimbang secara langsung dan/atau menggunakan persamaan (3):

$$
S Y=R C \times S P
$$

$S Y$ : hasil pati $(\mathrm{kg})$

$R C$ : kapasitas pemarutan $(\mathrm{kg} / \mathrm{jam})$

SP: rendemen pati $(\%)$

\section{Kehilangan pati pada ampas (starch losses)}

Untuk menentukan jumlah pati yang tidak terbebas dan masih terikut pada ampas, sebanyak $100 \mathrm{~g}$ sampel ampas diambil untuk diproses lebih lanjut. Sampel ampas diblender selama 5 menit yang dimaksudkan untuk merusak dinding sel jaringan empulur yang belum rusak saat proses pemarutan. Setelah diblender, pati yang terdapat pada ampas diekstrak secara manual menggunakan saringan dari kain safir. Persentase kehilangan pati pada ampas dihitung menggunakan persamaan (4):

$$
P a=\frac{m_{p a}}{m_{a}} \times 100 \%
$$

$P a:$ persentase pati pada ampas (\%)

$m_{p a}$ : masa pati pada ampas $(\mathrm{kg})$

$m_{a}$ : massa ampas $(\mathrm{kg})$.

\section{Konsumsi bahan bakar bensin (fuel)}

Penggunaan bahan bakar bensin selama periode waktu tertentu diukur secara langsung menggunakan gelas ukur.

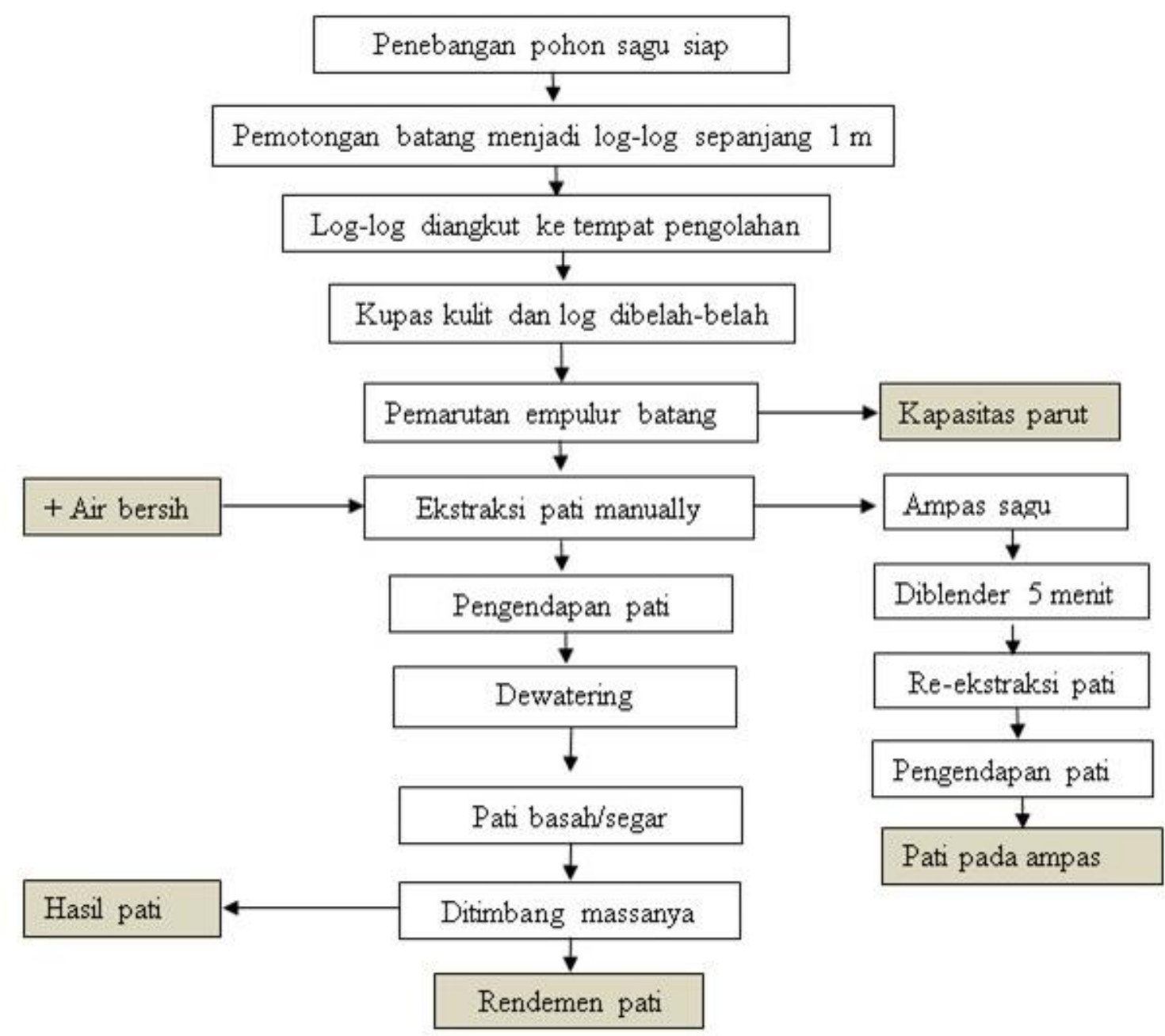

Gambar 2. Diagram alir proses pengolahan sagu untuk uji lapang mesin pemarut sagu tipe silinder bertenaga motor bakar bensin 


\section{HASIL DAN PEMBAHASAN}

\section{Kapasitas pemarutan}

Mesin parut yang diuji adalah tipe silinder dengan sistem pengupasan kulit batang, jadi sebelum dilakukan proses pemarutan, terlebih dahulu log-log sagu dikuliti dan dibelah-belah agar ukurannya sesuai untuk proses pemarutan (Gambar 3).
Proses pemarutan dilakukan dengan menempelkan dan mendorong potongan empulur batang ke permukaan silinder penghancur. Empulur hasil parutan dimasukkan ke dalam karung goni kemudian ditimbang massanya untuk perhitungan kapasitas pemarutan (Gambar 4). Hasil pengukuran kapasitas pemarutan untuk mesin pada petani-1 dan petani-2 disajikan pada Tabel 1.

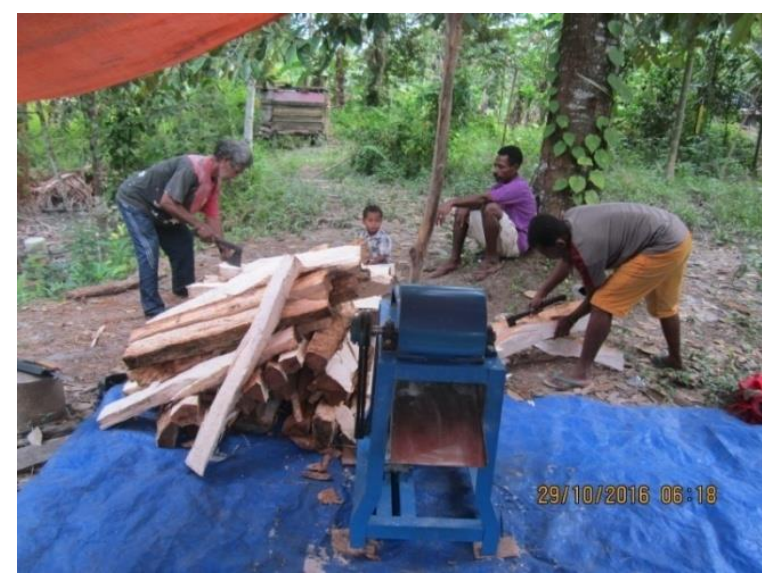

b

Gambar 3 Proses pengupasan kulit batang (a), dan pembelahan empulur batang (b)

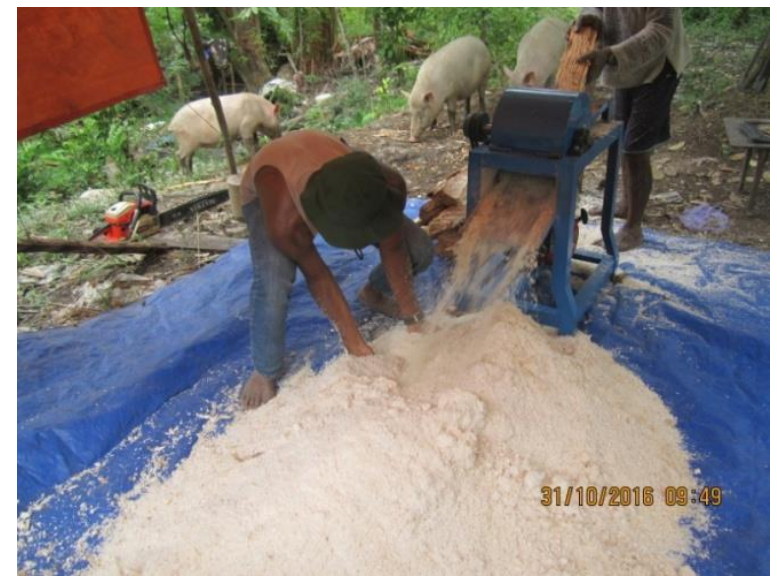

a

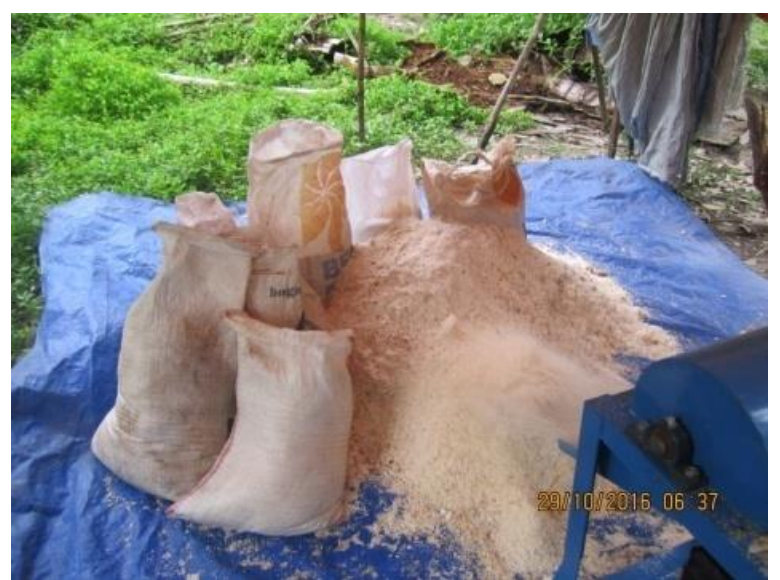

b

Gambar 4 Empulur hasil parutan (a), selanjutnya dimasukkan ke dalam karung (b) untuk kemudian ditimbang sebelum diproses lebih lanjut. 
Tabel 1. Kapasitas pemarutan mesin pada petani-1 dan petani-2

\begin{tabular}{cccccccc}
\hline \multirow{2}{*}{ Ulangan } & \multicolumn{2}{c}{ Massa ela $(\mathrm{kg})$} & \multicolumn{2}{c}{ Waktu pemarutan (jam) } & \multicolumn{3}{c}{ Kapasitas pemarutan (kg/jam) } \\
\cline { 2 - 8 } & Petani-1 & Petani-2 & Petani-1 & Petani-2 & Petani-1 & Petani-2 & Rata-rata \\
\hline 1 & 58 & 151 & 10 & 17 & 560 & 533 & 542 \\
2 & 136 & 144 & 16 & 17 & 525 & 508 & 516 \\
3 & 173 & 218 & 20 & 22 & 515 & 595 & 555 \\
4 & 198 & 148 & 19 & 18 & 633 & 493 & 563 \\
5 & 230 & 189 & 14 & 20 & 978 & 567 & 773 \\
6 & 128 & 184 & 9 & 21 & 877 & 526 & 701 \\
7 & 137 & 191 & 11 & 19 & 783 & 603 & 693 \\
\hline \multicolumn{3}{c}{ Rata-rata } & & 694 & 546 & 620 \\
\hline \multicolumn{3}{c}{ Standard deviasi } \\
\hline
\end{tabular}

Berdasarkan Tabel 1 terlihat bahwa kapasitas pemarutan rata-rata yaitu 620 $\mathrm{kg} / \mathrm{jam}$. Kapasitas pemarutan mesin pada petani-1 $(694 \mathrm{~kg} / \mathrm{jam})$ lebih tinggi dari petani-2 (546 kg/jam). Perbedaan kapasitas pemarutan ini disebabkan karena keterampilan (skill) petani-1 lebih tinggi daripada keterampilan petani-2. Berdasarkan informasi yang diperoleh di lokasi penelitian, diketahui bahwa petani-1 telah berpengalaman menggunakan mesin pemarut sagu karena sebelumnya telah memiliki mesin pemarut sagu dari bantuan pemerintah, sedangkan petani-2 baru pertama kali mengoprasikan mesin pemarut sagu. Disamping itu, diduga tingkat kekerasan empulur sagu yang diolah pada petani-2 lebih tinggi (lebih keras) dibandingkan dengan kekerasan empulur pada petani-1. Salah satu faktor yang mempengaruhi tingkat kekerasan empulur batang adalah umur tanaman (growing stage). Pohon sagu yang diolah menggunakan petani-2 berumur lebih tua daripada pohon sagu yang diolah petani-1. Hal ini terlihat dari tinggi pohon yang diolah petani-2 jauh lebih tinggi dibandingkan dengan pohon sagu pada petani-1. Menurut Sitkey (1986), salah satu faktor yang mempengaruhi proses pemarutan adalah sifat mekanik bahan yang diproses. Sifat-sifat mekanik bahan tergantung pada tahap pertumbuhan (growing stage), kadar air dan posisinya dari arah pangkal atau dari arah ujung. Ketahanan pemotongan (cutting resistance) bagian tanaman yang lebih muda lebih rendah dari bagian tanaman yang lebih tua.Hal ini berhubungan dengan variasi tekstur sebagai akibat dari proporsi serat yang berbeda-beda menurut umur. Jadi tekstur dan ketahanan pemotongan (cutting resistance) fungsi dari umur.
Kapasitas pemarutan yang diperoleh pada penelitian ini konsisten dengan hasil penelitian Darma dkk., (2015) dan (2016), dan Thoriq dkk. (2017) yang memperoleh kapasitas pemarutan berturut-turut $635 \mathrm{~kg} / \mathrm{jam}$, $603 \mathrm{~kg} / \mathrm{jam}$ dan 649,38 kg/jam. Namun demikian, kapasitas parut yang diperoleh pada penelitian ini lebih tinggi dibandingkan dengan hasil penelitian Reniana dkk., (2017) dan Thompson (2011) yang menghasilkan kapasitas parut berturut-turut $322,52 \mathrm{~kg} / \mathrm{jam}$ dan $418 \mathrm{~kg} / \mathrm{jam}$. Kapasitas pemarutan tergantung pada tipe mesin, besarnya sumber tenaga penggerak, karakteristik gigi parut, karakteristik bahan yang diparut dan keterampilan operator.

\section{Rendemen pati dan hasil pati}

Empulur hasil parutan (ela) diekstrak patinya secara tradisional/manual menggunakan alat ekstraksi tradisional (Gambar 5). Proses ekstraksi diawali dengan memasukkan hancuran empulur batang sagu ke dalam wadah penampung yang telah dilengkapi dengan kain penyaring kemudian ditambahkan air secara terus menerus sambil diaduk dan diperas. Suspensi pati melewati kain penyaring dan ditampung di bak pengendapan pati yang terbuat dari kotak kayu berlapis terpal kedap air. Proses dihentikan manakala aliran suspensi/slurry dari alat ekstraksi ekstraksi sudah tidak mengandung pati lagi yang ditandai dengan suspense yang jernih. Suspensi pati dibiarkan selama 5 jam untuk kemudian air yang berada pada lapisan atas dibuang dan endapan pati dikumpulkan dan dikemas dalam karung goni (Gambar 6). Hasil pati ditimbang untuk perhitungan rendemen dan hasil pati. Pada Tabel 2 disajikan rendemen pati dan hasil pati dari 
pengujian mesin pada petani-1 dan petani-2. Perlu ditambahkan disini bahwa mesin yang digunakan oleh petani-1 dan petani-2 memiliki

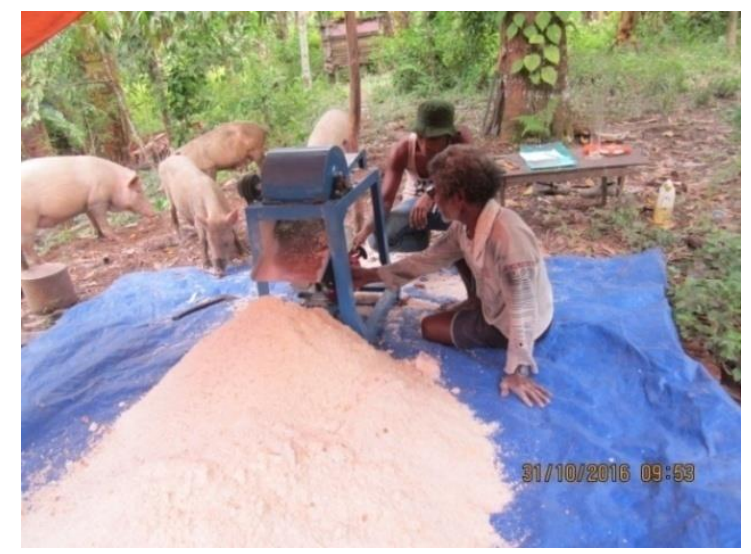

a spesifikasi yang sama, namun dioperasikan oleh keluarga yang berbeda. Demikian pula dengan pohon sagu yang diolah, juga berbeda.

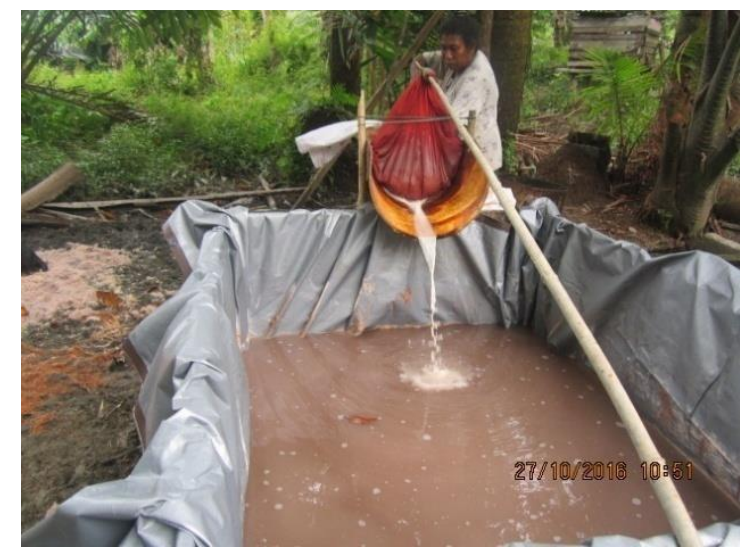

b

Gambar 5 Empulur hasil parutan siap untuk diekstraksi (a), dan proses ekstraksi pati secara tradisional (b)

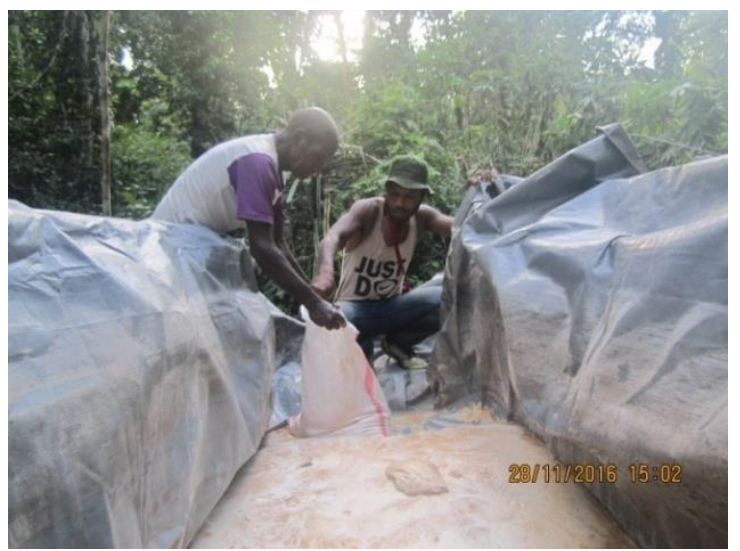

a

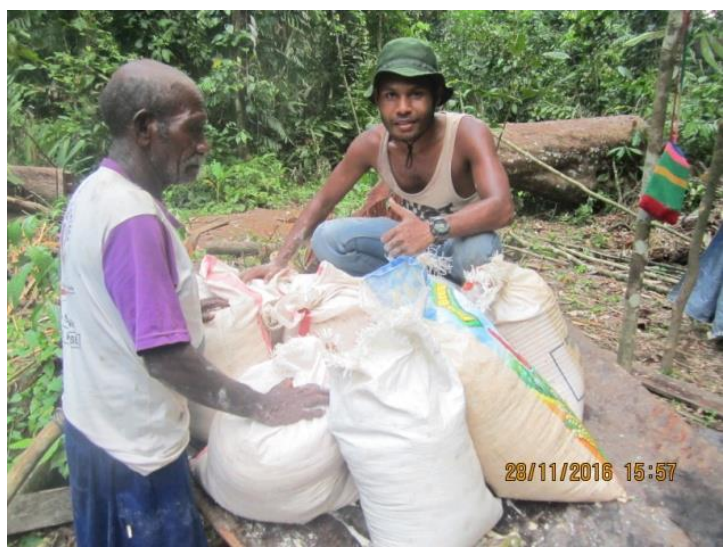

b

Gambar 6 Proses mengumpulkan pati hasil ekstraksi (a), dan kemasan pati dalamkarung goni (b)

Tabel 2. Rendemen pati dan hasil pati hasil pengolahan mesin pada petani-1 dan petani-2

\begin{tabular}{lccccc}
\hline Ulangan & $\begin{array}{c}\text { Massa } \\
\text { empulur } \\
\text { (kg/pohon) }\end{array}$ & $\begin{array}{c}\text { Waktu } \\
\text { pemarutan } \\
\text { (jam) }\end{array}$ & $\begin{array}{c}\text { Waktu } \\
\text { ekstraksi } \\
\text { (jam) }\end{array}$ & $\begin{array}{c}\text { Rendemen pati } \\
\text { basah (\%) }\end{array}$ & $\begin{array}{c}\text { Hasil pati } \\
\text { basah (kg) }\end{array}$ \\
\hline Petani-1 & 1.060 & 1,62 & 34,10 & 36 & 382 \\
\hline Petani-2 & 1.125 & 2,06 & 38,04 & 47 & 576 \\
\hline Rataan & 1.093 & 1,84 & 36.07 & 41,5 & 479 \\
\hline Standard deviasi & 45,96 & 0,31 & 2,79 & 7,78 & 137,18 \\
\hline
\end{tabular}

${ }^{*}$ : hancuran empulur hasil parut diekstraksi secara manual menggunakan alat ekstraksi tradisional yang biasa digunakan oleh masyarakat setempat sebagaimana terlihat pada Gambar 5 (b)

Berdasarkan Tabel 2 terlihat bahwa rendemen pati rata-rata adalah $41,5 \%$. Rendemen pati yang dihasilkan pada petani-2 (47\%) lebih tinggi dari rendemen pati hasil pengolahan petani-1 (36\%). Adanya perbedaan rendemen pati diantara kedua petani disebabkan karena adanya perbedaan kandungan pati pada empulur sagu yang diolah, bukan karena perbedaan kinerja mesin. Secara umum, rendemen pati dipengaruhi oleh 
teknik pengolahan dan kandungan pati pada bahan yang diolah. Rendemen pati yang dihasilkan yaitu berturut-turut $36 \%$ dan $47 \%$ untuk petani-1 dan petani-2 mendukung hasil penelitian Darma (2009) dan Darma dkk. (2013; 2017; 2019), kesemuanya menguji mesin parut sagu tipe silinder dengan berbagai karakteristik gigi parut dengan hasil rendemen pati berturut-turut $31 \%, 38.23 \%, 44.34 \%$ dan $38,5 \%$. Namaun, lebih tinggi dibandingkan dengan hasil penelitian Hermanto dkk., (2011), Irawan (2007) dan Thoriq dkk., (2017) yang menghasilkan rendemen pati berturut-turut $19.31 \%, 17.07 \%$, dan $15,14 \%$. Hasil penelitian Reniana dkk., (2017), dan Payung (2009) menghasilkan rendemen pati berturut-turut $37,44 \%$, dan 30 - 36\%. Darma (2011), melaporkan bahwa rendemen pati sagu di berbagai lokasi di Papua dan Papua Barat berkisar antara $12.43 \%-39.89 \%$. Menurut Singhal dkk., (2008) kandungan pati pada empulur sagu siap panen berkisar antara 18,8\%-38,8\%, sedangkan menurut Flach (1997), kandungan pati pada empulur batang sagu 10-25\%. Jong dan Ho (2011) melaporkan bahwa kandungan pati kering pada empulur batang sagu yang berasal dari hutan-hutan sagu alam di Sorong Selatan rata-rata 12,5\%. Yamamoto (2011) melaporkan bahwa persentase pati pada empulur batang sagu di sekitar Danau Sentani Jayapura, Papua berkisar antara 22,1\%-75,4\%. Yamamoto (2011) menggunakan metode kimia (chemicals method) untuk penentuan kadar pati, bukan metode konvensional.

Hasil pati basah (starch yield) sebagaimana terlihat pada Tabel 2 adalah 382 $\mathrm{kg}$ pada petani-1 dan $576 \mathrm{~kg}$ pada petani-2.
Hasil atau produksi pati per pohon tidak hanya tergantung pada kandungan pati dalam batang tapi juga pada diameter dan tinggi batang (volume batang). Di daerah Papua dan Papua Barat, rata-rata produksi pati sagu basah adalah 317 kg/pohon (Darma dkk., 2011). Hasil penelitian Saunggay (2019) di Distrik Supiori Selatan menghasilkan produksi pati basah 681 $\mathrm{kg}$ per pohon. Yamamoto (2011) melaporkan bahwa produksi pati kering per pohon berkisar antara 200-500 kg, sedangkan menurut Konuma (2018) produksi pati kering antara 150-300 kg per pohon. Abidin dkk., (2019) melaporkan bahwa rata-rata produksi pati basah di daerah Konawe Sulawesi Tenggara berkisar antara $350 \mathrm{~kg}-450 \mathrm{~kg}$ per pohon.

\section{Persentase kehilangan pati pada ampas dan konsumsi bahan bakar}

Hasil pati (starch yield) yang dapat terekstrak (starch recovery) pada proses ekstraksi hanyalah jaringan empulur yang dinding selnya telah hancur pada proses pemarutan. Jadi hasil pati tergantung pada proporsi sel-sel yang dindingnya telah robek/rusak, tergantung pada tingkat kehalusan hasil parutan.Untuk mengevaluasi kehilangan pati pada ampas (unextracted starch) sampel ampas $100 \mathrm{~g}$ dihancurkan lebih lanjut menggunakan blender selama 5 menit. Pada saat diblender ditambahkan air secukupnya untuk mempermudah proses penghancuran. Pati yang terkandung pada ampas hasil blender kemudian di re-ekstrak secara manual (Gambar 7). Pati yang dihasilkan kemudian ditimbang dan dibagi massa ampas. Selanjutnya persentase kehilangan pati dihitung menggunakan persamaan 4 .

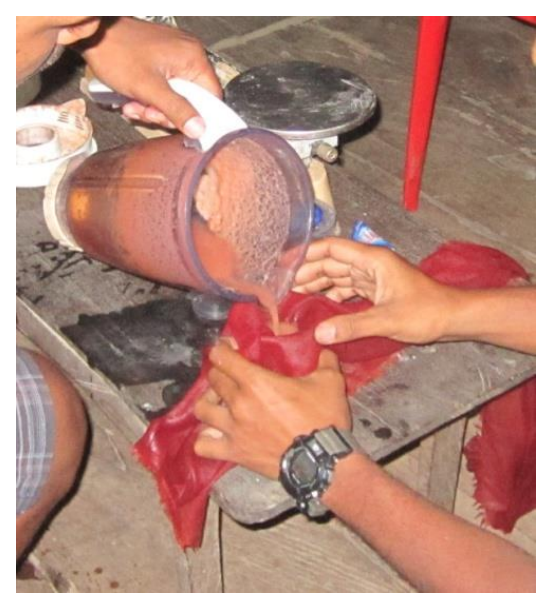

a

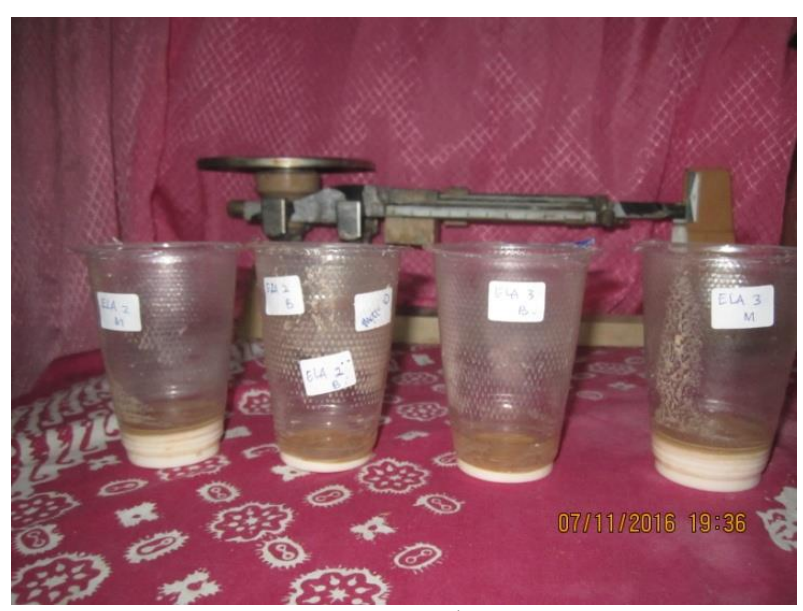

b

Gambar 7. Sampel ampas 100 g diblender kemudian re-ekstraksi (a) dan pati yang dihasilkan (b) 
Konsumsi atau penggunaan bahan bakar diukur secara langsung menggunakan gelas ukur pada setiap periode waktu pemarutan tertentu. Periode waktu pemarutan pada penelitian ini untuk setiap pengukuran konsumsi bahan bakar bervariasi antara 9-22 menit, disesuaikan dengan kemampuan pekerja untuk segera mengolah lebih lanjut empulur hasil parutan (proses ekstraksi). Proses pemarutan dilakukan secara bertahap untuk menghindari kerusakan empulur hasil parutan akibat keterlambatan proses ekstraksi.

Pada Tabel 3 disajikan persentase kehilangan pati pada ampas dan konsumsi bahan bakar bensin per jam.

Tabel 3. Kehilangan pati pada ampas dan konsumsi bahan bakar mesin pada petani-1 dan petani-2

\begin{tabular}{ccccccc}
\hline & \multicolumn{2}{c}{ Kehilangan pati pada ampas $(\%)$} & \multicolumn{3}{c}{ Konsumsi bahan bakar (liter/jam) } \\
\cline { 2 - 7 } Ulangan & Petani-1 & Petani-2 & Rata-rata & Petani-1 & Petani-2 & Rata-rata \\
\hline 1 & 4 & 8 & 6 & 1,2 & 1,0 & 1,1 \\
2 & 5 & 7 & 6 & 1,2 & 0,7 & 0,9 \\
3 & 6 & 9 & 7 & 1,5 & 1,0 & 1,2 \\
4 & 6 & 6 & 6 & 1,3 & 0,8 & 1,0 \\
5 & 6 & 9 & 8 & 1,3 & 1,1 & 1,1 \\
6 & 5 & 9 & 7 & 1,4 & 0,9 & 1,1 \\
7 & 7 & 8 & 7 & 0,9 & 0,8 & 0,8 \\
\hline Rataan & 5,57 & 8,0 & 7 & 1,2 & 0,9 & 1,1 \\
\hline SD & 0,93 & 1,07 & 0,7 & 0,20 & 0,13 & 0,2 \\
\hline
\end{tabular}

Berdasarkan Tabel 3 meperlihatkan bahwa persentase kehilangan pati pada ampas rata-rata sebesar $7 \%$. Terlihat pula bahwa kehilangan pati terikut ke ampas pada petani-1 $(5,57 \%)$ lebih rendah daripada petani-2 $(8 \%)$. Semakin tinggi persentase pati pada ampas berarti semakin besar tingkat kehilangan hasil pati akibat tidak terekstrak dan terbuang bersama ampas. Persentase kehilangan pati pada ampas yang dihasilkan pada penelitian ini konsisten dengan hasil penelitian Darma dkk., (2011; 2015) yang memperoleh persentase kehilangan pati terikut ke ampas berturut-turut antara 5,79-6,45\% dan 7,33\%-8,83\%. Hasil ini juga sejalan dengan hasil penelitian Thompson (2011) yang memperoleh persentase pati pada ampas 5,8\%.

Persentase kehilangan pati terikut ke ampas sangat dipengaruhi oleh ukuran partikel/derajat kehalusan empulur hasil parutan dan kandungan pati pada empulur. Semakin halus ukuran partikel hasil parutan maka persentase kehilangan pati pada ampas semakin kecil. Dari sisi kandungan pati pada empulur, semakin tinggi kadar pati (starch content), semakin tinggi pula persentase kehilangan pati pada ampas. Idealnya, diharapkan tidak ada kehilangan pati yang terikut ke ampas, namun dalam prakteknya hal tersebut tidak bisa dihindari.
Konsumsi bahan bakar bensin untuk mesin pada petani-1 dan petani-2 berturut-turut 1,2 liter/jam dan 0,9 liter/jam (rata-rata 1,1 liter/jam) (Tabel 3). Konsumsi bahan bakar tergantung pada rpm yang digunakan pada saat proses pengolahan dan tingkat beban (load) yang diberikan. Semakin tinggi rpm dan beban yang diberikan maka konsumsi bahan bakar semakin tinggi. Pada pengujian ini kedua mesin disetting pada rpm yang sama dalam kondisi tanpa beban. Konsumsi bahan bakar yang lebih tinggi pada mesin pada petani-1 menunjukkan bahwa motor penggerak menerima beban yang lebih besar dibandingkan dengan petani-2. Beban yang diterima motor penggerak berbanding lurus dengan daya dorong operator saat proses pemarutan berlangsung. Hal ini terbukti dari kapasitas pemarutan pada mesin pada petani-1 lebih tinggi, mengindikasikan bahwa operator mendorong empulur ke silinder penghancur dengan gaya yang lebih besar dibandingkan dengan yang terjadi pada petani-2.

\section{KESIMPULAN}

Telah dilakukan pengujian lapangan mesin pemarut sagu tipe silinder bertenaga motor bakar bensin. Uji lapang dilakukan dengan menggunakan 2 unit mesin pemarut sagu dan melibatkan 2 keluarga pemilik dusun 
sagu di Kampung Masni, Distrik Masni, Kabupaten Manokwari. Dari hasil uji lapang diperoleh performansi mesin pemarut sagu tipe silinder bertenaga motor bakar yaitu:

(a) Kapasitas pemarutan $620 \mathrm{~kg} / \mathrm{jam}$.

(b) Rendemen pati $41,5 \%$.

(c) Hasil pati basah $479 \mathrm{~kg} /$ pohon.

(d) Kehilangan pati pati pada ampas $6,79 \%$.

(e) Konsumsi bahan bakar bensin 1,05 liter/jam.

\section{UCAPAN TERIMA KASIH}

Penulis menyampaikan apresiasi dan terima kasih kepada Kementerian Riset, Teknologi dan Pendidikan Tinggi c.q. Direktorat Penelitian dan Pengabdian Kepada Masyarakat atas dukungan dana untuk penelitian ini melalui program Iptek bagi Masyarakat.

\section{DAFTAR PUSTAKA}

Abidin, Z., Bungati dan Musadar. 2019. Analisis Kelayakan dan Perspektif Pengembangan Pengolahan Sagu di Sulawesi Tenggara. Jurnal Pengkajian dan Pengembangan Teknologi Pertanian Vol. 23, No.3:301-313

Bintoro, M.H, (2011), Progress of sago research in Indonesia. In: Proc $10^{\text {th }}$ int sago symposium: sago for food security, bio-energy, and industry from research to market. Bogor, pp 16-34.

Cecil, J.E, (1992), Small-, medium-and largescale starch processing. Rome: FAO Agricultural Services Bulletin 98.

Darma, (2009), Prototype of cylinder type sago rasper powered by $5.5 \mathrm{hp}$ gasoline engine. Agrotek Journal1(6):49-56.

Darma, (2010). Starch content and production potency of natural sago palm (Metroxylon sagu Rottb). Agrotek J2(2):7-14.

Darma, (2011), Traditional processing of sago in Papua Province. In Proc $10^{\text {th }}$ int sago symposium: sago for food security, bioenergy, and industry from research to market. Bogor, 29-31 October, pp 115116.

Darma, Xiulun Wang, and Koji Kito, 2013, Improvement of Cylinder Type Sago Rasper Using Sharp Pointed Teeth in: Prooceedings of the $11^{\text {th }}$ International
Sago Symposium, November $6-8$, 2013. Manokwari, Indonesia.

Darma, Xiulun Wang, and Koji Kito, 2014,.Development of Cylinder Type Sago Rasper for Improving Rasping Performance. International Agricultural Engineering Journal (IAEJ) Vol. 23, No.3:31-40.

Darma dan Budi Triyanto. 2015. Development and Performance Test of Cylinder Type Sago Rasper Powered by Petrol Engine. Prosiding Seminar Nasional PERTETA 5 - 7 Agustus, 2015. Universitas Hasanuddin. Makassar.

Darma, Xiulun Wang, and Koji Kito, 2015, Effect of Teeth Density and Cylinder Rotation Speed on Power Requirement and Specific Energy Consumption of Cylinder Type Sago Rasper in: Prooceedings of the $12^{\text {th }}$ International Sago Symposium September $15-17$, 2015. Tokyo, Japan.

Darma dan A. Kurniawan. 2016. Effect of Cylinder Rotation Speed, Teeth Density and Engine Power Rate on Performance of Cylinder Type Sago Rasping Machine. in: The $1^{\text {st }}$ international conference : The role of agricultural engineering for sustainable agricultural production (AESAP). 13-14 Desember, 2016, IPB Bogor.

Darma, B. Santoso, Reniana. 2017. Development of cylinder type sago rasping machine using pointed teeth. International Journal of Engineering and Technology (IJET-IJENS) Vol. 17, No.01: 2472-2481.

Darma, B. Santoso, M. A. Arbianto. 2019. Effect of Hopper Angle and Teeth Density on Performance of Cylinder Type Sago Rasping Machine.Proceeding of the $3^{\text {rd }}$ International Symposium on Agricultural and Biosystem Engineering. IOP Conf. Series: Earth and Environmental Sciences 355 (2019) 012114.

Djoprie, M.H.B, S. Herodian dan Ngadiono (2014). Sagu untuk Kesejahteraan Masyarakat Papua: suatu kajian dalam upaya pengembangan sagu sebagai komoditas unggulan di Provinsi Papua dan Papua Barat. Laporan Penelitian Unit Percepatan Pembangunan Papua dan Papua Barat. Jakarta. 
Flach, M. 1997. Sago Palm. Metroxylon sagu Rottb .International Plant Genetic Resources Institute (IBPGR). Rome.

Hermanto, A., Nuwiyah, and Muhidin.2011. Perbedaan Teknik Pemarutan dan Pengaruhnya Terhadap Peningkatan Rendemen dan Kualitas Pati.increasing starch percentage and starch quality. Agriplus Scientific Journal,21(1): 3035.

Irawan P. 2009. Rancangan dan Uji Teknis Alat Parut Sagu Tipe Silinder. Skripsi Sarjana. Institut Pertanian Bogor. Bogor.

Jong, F. S. and C.J. Hoo. 2011. Growth and Yields of Natural Sago Forests for commercial operations. In Proc. $10^{\text {th }}$ Int.Sago Symposium, Sago for food security, Bio-energy, and Industry from Research to Market,43-45.Bogor, Indonesia, Oct. 29-31.

Jong, F.S. 2018. An Overview of Sago Industry Development, 1980s-2015. in: SAGO PALM: Multiple Contribution to Food Security and Sustainable Livelyhoods (Eds: Ehara, H., Y. Toyoda and D.V. Johnson). Springer. Singapore.

Manan, D. M. A. 2011. Optimization of sago starch extraction using drum rasper in Proc. $10^{\text {th }}$ Int.Sago Symposium: Sago for food security, Bio-energy, and Industry From Research to Market, 93-95. Bogor 29-31 October.

Matanubun H, Maturbongs L (2006) Sago palm potential, biodiversity and sociocultural consideration for industrial sago development in Papua, Indonesia. In Proc. $8^{\text {th }}$ Int. Sago Symposium: Sago
Palm Development and Utilization,Jayapura, pp 41-54.

Payung, P. 2009. Design and performance test of disc type sago rasper (Metroxylon $\mathrm{sp}$ ). Agrotek Journal 1(4):32-37.

Reniana, Darma dan A. Kurniawan. 2017. Prototipe Mesin Parut Empulur Sagu Bertenaga Motor Bakar. Jurnal Teknik Pertanian Lampung Vol. 6 No.2 Hal: 8994.

Sauggay, R. 2019. Studi Pengolahan Sagu (Metroxylon sp) Secara Mekanis di kampung Warbefondi Distrik Supiori Selatan Kabupaten Supiori Provinsi Papua. Skripsi Fakultas Teknologi Pertanian UNIPA. Manokwari.

Singhal, R.S., J. F. Kennedy, S. M. Gopalakrishnan, A. Kaczmarek, C. J. Knill, and P. F. Akmar.2008. Industrial production-processing, and utilization of sago palm-derived products.Science Direct Carbohydrate Polymers, 72: 120. Elsevier.

Sitkey, G. 1986. Mechanics of Agricultural material. ELSEVIER. Amsterdam.

Thoriq A. dan A. Sutejo. 2017. Desain dan Uji Kinerja Mesin Pemarut Sagu Tipe TPB 01. Jurnal Agritech Vol. 37 No.4 Hal: 453-461.

Worabai, T. 2011. Pengembangan Desain Alat Parut Sagu (Metroxylon sp) Tipe Silinder Bertenaga motor Bakar. Skripsi Fakultas Pertanian dan Teknologi Pertanian UNIPA.Manokwari.

Yamamoto. Y. 2011. Starch Productivity of Sago Palm and Related Factors in Proc. $10^{\text {th }}$ Int.Sago Symposium: Sago for food security, Bio-energy, and Industry From Research to Market, 93-95. Bogor 29-31 October. 